Open Access

\title{
Correlating quantitative real-time PCR to rapid diagnostic test and RNA transcript expression in isolated gametocytemia and asexual parasitemia of Plasmodium falciparum malaria
}

\author{
Rachel Lau', Melissa Phuong ${ }^{2}$, Filip Ralevski ${ }^{1}$ and Andrea K. Boggild ${ }^{1,3,4^{*}}$
}

\begin{abstract}
Background: At present, only microscopic examination of stained thick and thin blood smears for malaria can differentiate clinically relevant asexual parasitemia from clinically irrelevant isolated gametocytemia. Microscopy is time consuming, labour intensive, and requires significant technical expertise to perform. Simple and rapid tests that can distinguish asexual from isolated sexual parasitemia are needed.

Methods: To determine if parasitemia and cycle threshold $\left(C_{T}\right.$ values on Plasmodium genus and $P$. falciparum-specific quantitative polymerase chain reaction ( $\mathrm{PPCR}$ ) assays correlate to positivity of rapid diagnostic test (RDT), and 18S rRNA gene copy number, we analyzed blood samples from Ontario patients with isolated $P$. falciparum gametocytemia or asexual stages. RNA transcripts were evaluated to determine whether there is correlation of expression to different life cycle stages of $P$. falciparum.

Results: 45 specimens containing isolated $P$. falciparum gametocytes, and 40 specimens containing isolated asexual stages by microscopy were identified and analyzed. By RDT, 40 of 45 (88.9 \%) isolated gametocytemia specimens and 40 of $40(100 \%)$ asexual-stage specimens were positive for Plasmodium falciparum-specific histidine rich protein-2 (HRP-2). Fourteen of 45 (31.1\%) isolated gametocytemia specimens, and 36 of 40 (90\%) asexual-stage specimens were positive for Plasmodium genus aldolase T2 band. Positivity of the aldolase T2 band was associated with lower mean Plasmodium genus and $P$. falciparum-specific $C_{T}$ values, and to higher mean $18 \mathrm{~S}$ rRNA gene copy by $\mathrm{QPCR}$ for both isolated gametocytemia and asexual-stage specimens. There was also a negative correlation of asexual parasitemia to both $C_{T}$ values, and positive correlation to $18 \mathrm{~S}$ rRNA gene copy number. Analysis of asexual stage-specific erythrocyte binding antigen (eba-175) transcripts on 25 isolated gametocytemia and 20 asexual-stage specimens gave a positive predictive value of $62.5 \%$ and negative predictive value of $100 \%$ for asexual parasitemia. Thus, an absence of eba-175 transcripts excluded the presence of asexual (clinically relevant) parasitemia.

Conclusions: Positivity of the aldolase T2 band of BinaxNow RDT correlated to higher parasite load in both isolated gametocytemia and asexual-stage specimens. Asexual stage-specific eba-175 RNA transcript expression provided reasonable negative predictive value for exclusion of asexual parasitemia in clinical samples, but was present in both isolated gametocytemia and asexual stage specimens.
\end{abstract}

\footnotetext{
*Correspondence: andrea.boggild@utoronto.ca

'Public Health Ontario Laboratories, Public Health Ontario, Toronto, Canada

${ }^{3}$ Tropical Disease Unit, Division of Infectious Diseases, UHN-Toronto General Hospital, 200 Elizabeth Street, 13EN-218, Toronto, ON M5G 2C4, Canada

Full list of author information is available at the end of the article
} 


\section{Background}

Prompt and accurate diagnosis of malaria is essential to limiting morbidity and mortality due to this imported parasitic infection [1]. Several tests are employed in the clinical parasitology laboratory to diagnose malaria, and these commonly include thick and thin Giemsa-stained blood smears for direct examination of parasitized erythrocytes; rapid antigen detection via immunochromatographic test; and amplification of parasite genomic material via PCR using qualitative or quantitative assays. Each of these laboratory tests has its own advantages and limitations, and unique performance characteristics $[2,3]$. However, only direct examination of blood smears can, to date, reliably differentiate asexual parasitemia, which is clinically relevant, from sexual parasitemia or gametocytemia, which is clinically irrelevant meaning that these stages do not require treatment for resolution of malaria. Isolated gametocytemia is relevant from a public health perspective, as gametocytes are infectious to biting Anopheles mosquitoes present in parts of North America. Although rapid diagnostic (antigen) tests (RDTs) are a useful adjunct to direct examination of blood smears, they are unable to distinguish current from past infection due to antigen persistence following infection [4, 5], and the presence of gametocytes [6]. Similarly, commonly employed PCR assays amplify conserved targets, such as $18 \mathrm{~S}$, present in both asexual and sexual stage parasites $[7,8]$.

Understanding a patient's parasitemia status over time will guide the course of treatment. If a patient remains symptomatic while on malaria treatment due to the presence of asexual stages (and potentially increasing asexual parasitemia), then this may reflect drug resistance or clinical failure. Conversely, if that patient remains symptomatic with fever but only sexual parasitemia is noted, then an alternate explanation for ongoing or recurrent symptoms would be pursued, rather than invoking drug-related issues. As RDT will remain positive for weeks after treatment [4, 5], and expertise in microscopy at hospital-based hematology laboratories is becoming increasingly scarce, PCR is playing an increasingly important and relevant role in the clinical management of malaria patients. Thus, identifying non-microscopy based tests with equal ability to identify stage and quantitation of parasites as microscopy is essential as our understanding of a patient's ongoing parasitemia stage has direct clinical relevance.

The extent to which quantitative real time PCR results correlate to level of positivity on rapid diagnostic tests (RDTs) or $\mathrm{C}_{\mathrm{T}}$ values when isolated gametocytemia is present in clinical samples is unknown, but could be useful for delineating laboratory "markers" or flags of isolated sexual parasitemia (gametocytemia) when smear results are unavailable or non-diagnostic for either quantitation or species identification. We sought to determine if parasitemia and $C_{\mathrm{T}}$ values on Plasmodium genus and P. falciparum-specific PCR assays and $18 \mathrm{~S}$ rRNA gene copy number by quantitative real time PCR correlate to positivity of RDT in clinical samples from Ontario containing isolated $P$. falciparum gametocytemia or asexual stages by expert microscopy. As well, we evaluated RNA transcript markers that may differentiate sexual from asexual stages of $P$. falciparum.

\section{Methods}

\section{Clinical samples}

Samples included in this analysis were 45 biobanked malaria specimens with isolated $P$. falciparum gametocytemia noted at microscopy, and a random sampling of 10 each of specimens with the following ranges of $P$. falciparum asexual parasitemia (rings, trophozoites, and/or schizont stages) quantitated by expert microscopy: $<0.1 ; 0.1-1.0$; $1.0-10.0$; and $>10.0 \%$. Anonymized parasitologic data on positive malaria specimens examined at the Public Health Ontario Laboratories (PHOL) were also extracted from the secure biobank database, and analyzed.

\section{Rapid diagnostic test}

Rapid diagnostic test (RDT) results for each specimen were acquired at the time of specimen processing in the clinical parasitology laboratory using the BinaxNOW Malaria RDT kit (Inverness Professional Medical Diagnostics, Scarborough, ME). Results were expressed as "positive" or "negative" at each of the Plasmodium falciparum-specific histidine rich protein-2 (HRP-2) and Plasmodium genus aldolase T2 bands, and were not quantified subjectively or objectively.

\section{Isolation of parasite and human DNA}

$200 \mu \mathrm{L}$ of frozen whole blood from each specimen were thawed from $-80{ }^{\circ} \mathrm{C}$ freezer. DNA were extracted with QIAamp DNA Mini kit (QIAGEN Sciences, Germantown, MD) using the DNA extraction protocol for blood. $60 \mu \mathrm{L}$ of DNA were eluted for each specimen.

\section{Plasmodium qualitative and quantitative real time PCR}

Plasmodium Genus and P.falciparum/P.vivax duplex species-specific real time PCR (qPCR) assays on $18 \mathrm{~S}$ rRNA were performed in triplicate, and P.malariae/ P.ovale duplex species-specific qPCR to exclude mixed infections were performed, as described [7, 8]. Human macro-globin qPCR were run as a positive extraction control [9]. To quantitate the $18 \mathrm{~S}$ rRNA gene copy number for each clinical sample in the reaction, control $P$. falciparum DNA was serially diluted ranging from 11.7 million to 0.117 gene copies/reaction and was included in each run. $\log$ gene copy numbers vs $C_{T}$ values were plotted, and the standard curve and equation generated 
were used to back calculate the gene copy number for each clinical sample. Parasitemia of $<0.1 \%$ was assigned a value of 0.01 in order to determine the correlation between parasitemia with $C_{\mathrm{T}}$ values and copy number. Average gene copy number for each sample was calculated from Plasmodium genus and P. falciparum species-specific qPCR runs.

Isolation of parasite and human RNA and CDNA synthesis RNA was extracted from $200 \mu \mathrm{L}$ of frozen whole blood using Macherey-Nagel Nucleospin RNA Blood Kit (Bethlehem, PA) with DNase digestion and eluted with $60 \mu \mathrm{L}$ nuclease-free water. $15 \mu \mathrm{L}$ of RNA was used for cDNA synthesis with Quanta qScript cDNA Synthesis Kit (Cat\# 95047-100, Quanta Biosciences, Gaithersburg, MD).

\section{Asexual stages transcript expression}

To determine if there was differential transcript expression between sexual and asexual stages samples, RNA transcripts of three genes were analyzed: erythrocyte binding antigen 175 (eba-175), chloroquine resistance transporter $(p f c r t)$ and merozoite apical erythrocyte binding ligand (maebl), which were previously shown to be expressed exclusively in the asexual stages of $P$. falciparum [10-12]. Forward and reverse primers spanning exon/intron junctions to avoid any false positives on residual DNA in the RNA extracts were designed for asexual stage-specific expression erythrocyte binding antigen 175 gene (eba-175, Gene ID: 2654998) fwd 5' GGAGGCTTTTTCAAGTATGGCCA 3', rev 5' CATAACTCCTTCAGAACTTTGA 3'; Plasmodium falciparum chloroquine resistance transporter (pfcrt, Gene ID: 2655199) fwd 5' AAACACAGTCGTAGAGAAT TGTGGTC 3', rev 5' AATGCGAAGGTTTTCCATGCT 3'; maebl (Gene ID: 811029) fwd 5' TTTAAAAAAA AGGAATTTTCAAACATG 3', rev 5' GTAGC TTCTTCAAACCACTTTC 3 ' and housekeeping myosin gene as extraction control (Gene ID: 813699) fwd 5' TAT CAGAGACAAAAATAAAGTTTG $3^{\prime}$ and rev' 5' CGAATCAAATAAGTCTAAATTTCG 3'. RNA transcripts were amplified with Amplitaq Gold Fast Master Mix (Life Technologies), 500nM of each primer and $2 \mu \mathrm{L}$ of cDNA in a total volume of $20 \mu \mathrm{L}$. PCR conditions were $95{ }^{\circ} \mathrm{C}$ for $10 \mathrm{~min}$ followed by 40 cycles of $96{ }^{\circ} \mathrm{C}$ for $5 \mathrm{~s}$, $60{ }^{\circ} \mathrm{C}$ (pfcrt) $/ 58{ }^{\circ} \mathrm{C}$ (eba-175)/56 ${ }^{\circ} \mathrm{C}$ (maebl and myosin) for $5 \mathrm{~s}, 68{ }^{\circ} \mathrm{C}$ for $5 \mathrm{~s}$ with a final extension of $72{ }^{\circ} \mathrm{C}$ for 30 s. $10 \mu \mathrm{L}$ of amplified product was visualized on $2.5 \%$ Agarose gel at $100 \mathrm{~V}$ for $1 \mathrm{~h}$ and stained with ethidium bromide. The intensity of the eba-175 positive bands was quantitated by Quantity One software (BioRad, Hercules, $\mathrm{CA}$ ) and percentage over background was calculated.

\section{Statistical analysis}

Descriptive statistics were performed for all continuous and categorical parasitologic variables. Differences between categorical variables were compared using Fisher's Exact Test. Differences between continuous variables were compared using Student's $t$-test, or in the case of non-normally distributed variables, Mann Whitney Rank Sum test. Correlation was performed with Pearson r. Performance characteristics of eba-175 PCR were calculated using microscopy as the gold standard. Sensitivity, specificity, positive predictive value (PPV), and negative predictive value (NPV) are reported for eba-175 transcript expression in asexual parasitemia. All statistical computations were performed using Graphpad Prism 5 (Graphpad Software, Inc. La Jolla, CA). Level of significance was set at $p<0.05$.

\section{Results}

\section{Clinical samples}

We identified 85 P. falciparum positive specimens from our de-identified malaria biobank, with storage at $-80 \mathrm{C}$ between August 2008 and April 2014. Forty-five specimens contained only sexual stages (gametocytes) by expert microscopy, and 40 contained only asexual stages (rings, trophozoites, schizonts) by expert microscopy. Of 45 isolated gametocytemia specimens, 34 had previously submitted specimens that were positive for isolated asexual stages, thus, the gametocytemia specimens were posttreatment in these 34 cases. For 11 specimens, no prior sample had been submitted. Parasitologic metrics are described in Table 1. All 45 isolated gametocytemia specimens had parasitemia of $<0.1 \%$, whereas the 40 asexualstage samples had parasitemias ranging from $<0.1$ to $34 \%$. All specimens were confirmed to contain isolate P. falciparum infection by species-specific qPCR.

\section{Rapid diagnostic test}

Forty of $45(88.9 \%)$ isolated gametocytemia specimens, were positive for Plasmodium falciparum-specific histidine rich protein-2 (HRP-2; T1 band) by Binax NOW RDT (Table 1). Fourteen of 45 isolated gametocytemia specimens $(31.1 \%)$ were positive for pan-Plasmodium aldolase (aldolase $\mathrm{T} 2$ band) by Binax NOW RDT (Table 1). All 40 isolated asexual-stages specimens were positive for the HRP-2 (T1) band, and 36 out of 40 (90\%) were positive for the aldolase T2 band (Table 2).

\section{Quantitative real time PCR of specimens with isolated gametocytemia}

Mean Plasmodium genus $\mathrm{C}_{\mathrm{T}}$ value for 44 specimens was $31.64 \pm 0.50$ (median 31.6, range 26.2-39.8). One specimen was undetectable by Plasmodium genus qPCR but was detectable by $P$. falciparum species-specific qPCR (Sample \#1, Table 1). Specimens with positive aldolase 
Table 1 Parasitologic factors, quantitative PCR results, and RNA transcript expression in 45 Plasmodium falciparum positive specimens with isolated gametocytemia by expert microscopy

\begin{tabular}{|c|c|c|c|c|c|c|c|c|c|c|c|}
\hline Sample & Microscopy & Parasitemia & HRP-2 T1 & Aldolase T2 & $\begin{array}{l}\text { Plasmodium } \\
\text { Genus Mean } C_{T}\end{array}$ & StDev & $\begin{array}{l}\text { P. falciparum } \\
\text { Mean } C_{T}\end{array}$ & StDev & $\begin{array}{l}\text { Ave } 18 \mathrm{~S} \text { rRNA } \\
\text { gene copy\#/rxn }\end{array}$ & eba-175 & myosin \\
\hline 1 & Gametocytes & $<0.1$ & + & - & 39.8 & 0.1 & - & - & 4 & + & + \\
\hline 2 & Gametocytes & $<0.1$ & + & - & - & - & 39.8 & 0.8 & 6 & + & - \\
\hline 3 & Gametocytes & $<0.1$ & + & - & 38.5 & 0.6 & 37.7 & 0.8 & 30 & + & + \\
\hline 4 & Gametocytes & $<0.1$ & - & - & 38.3 & 0.1 & 36.9 & 0.5 & 43 & ND & ND \\
\hline 5 & Gametocytes & $<0.1$ & - & - & 37.5 & 0.1 & 37.5 & 0.9 & 69 & ND & ND \\
\hline 6 & Gametocytes & $<0.1$ & + & - & 35.5 & 0.4 & 34.8 & 1.0 & 287 & ND & ND \\
\hline 7 & Gametocytes & $<0.1$ & + & - & 35.1 & 0.2 & 34.6 & 1.1 & 331 & ND & ND \\
\hline 8 & Gametocytes & $<0.1$ & + & - & 35.5 & 0.6 & 33.6 & 1.4 & 506 & ND & ND \\
\hline 9 & Gametocytes & $<0.1$ & + & - & 33.4 & 0.1 & 33.8 & 1.7 & 672 & ND & ND \\
\hline 10 & Gametocytes & $<0.1$ & + & - & 34.2 & 0.2 & 33.3 & 1.4 & 687 & ND & ND \\
\hline 11 & Gametocytes & $<0.1$ & + & - & 33.2 & 0.1 & 33.4 & 1.0 & 803 & ND & ND \\
\hline 12 & Gametocytes & $<0.1$ & + & - & 34.1 & 0.4 & 32.4 & 1.1 & 814 & ND & ND \\
\hline 13 & Gametocytes & $<0.1$ & + & - & 33.0 & 0.1 & 32.7 & 0.9 & 1046 & ND & ND \\
\hline 14 & Gametocytes & $<0.1$ & + & + & 33.2 & 0.3 & 32.4 & 0.8 & 1195 & + & + \\
\hline 15 & Gametocytes & $<0.1$ & + & - & 33.6 & 0.6 & 31.3 & 0.3 & 1214 & - & + \\
\hline 16 & Gametocytes & $<0.1$ & + & - & 32.5 & 0.4 & 31.7 & 0.5 & 1251 & + & + \\
\hline 17 & Gametocytes & $<0.1$ & + & - & 32.5 & 0.6 & 32.2 & 0.8 & 1422 & + & + \\
\hline 18 & Gametocytes & $<0.1$ & + & - & 33.5 & 0.4 & 31.1 & 0.8 & 1525 & ND & ND \\
\hline 19 & Gametocytes & $<0.1$ & + & - & 31.8 & 0.4 & 32.1 & 1.0 & 1754 & ND & ND \\
\hline 20 & Gametocytes & $<0.1$ & + & - & 31.6 & 0.3 & 32.1 & 1.2 & 1801 & ND & ND \\
\hline 21 & Gametocytes & $<0.1$ & + & - & 32.3 & 0.6 & 31.7 & 1.1 & 1854 & ND & ND \\
\hline 22 & Gametocytes & $<0.1$ & + & - & 31.5 & 0.3 & 31.3 & 0.0 & 1905 & + & + \\
\hline 23 & Gametocytes & $<0.1$ & - & - & 31.5 & 0.3 & 30.5 & 0.4 & 2530 & - & + \\
\hline 24 & Gametocytes & $<0.1$ & + & - & 32.2 & 0.8 & 30.9 & 0.8 & 2573 & - & + \\
\hline 25 & Gametocytes & $<0.1$ & + & - & 32.0 & 0.5 & 30.4 & 0.9 & 3267 & - & + \\
\hline 26 & Gametocytes & $<0.1$ & - & - & 30.7 & 0.3 & 31.0 & 1.2 & 3300 & - & + \\
\hline 27 & Gametocytes & $<0.1$ & + & - & 31.3 & 0.1 & 30.5 & 0.9 & 3422 & ND & ND \\
\hline 28 & Gametocytes & $<0.1$ & + & - & 30.2 & 0.3 & 29.9 & 0.2 & 4374 & + & + \\
\hline 29 & Gametocytes & $<0.1$ & + & - & 29.9 & 0.4 & 30.0 & 0.9 & 5640 & ND & ND \\
\hline 30 & Gametocytes & $<0.1$ & + & - & 30.2 & 0.1 & 29.7 & 0.7 & 5928 & - & + \\
\hline 31 & Gametocytes & $<0.1$ & + & + & 30.7 & 0.8 & 28.8 & 0.5 & 5967 & + & + \\
\hline 32 & Gametocytes & $<0.1$ & + & + & 30.0 & 0.1 & 29.3 & 0.8 & 7246 & ND & ND \\
\hline 33 & Gametocytes & $<0.1$ & + & + & 29.8 & 0.2 & 29.2 & 0.8 & 7694 & - & + \\
\hline 34 & Gametocytes & $<0.1$ & + & + & 29.6 & 0.2 & 28.9 & 0.9 & 8996 & - & + \\
\hline 35 & Gametocytes & $<0.1$ & + & - & 29.3 & 0.1 & 28.9 & 1.1 & 9686 & + & + \\
\hline 36 & Gametocytes & $<0.1$ & + & + & 28.6 & 0.4 & 29.1 & 1.0 & 10539 & ND & ND \\
\hline 37 & Gametocytes & $<0.1$ & - & + & 28.8 & 0.2 & 28.5 & 0.5 & 11110 & ND & ND \\
\hline 38 & Gametocytes & $<0.1$ & + & + & 28.4 & 0.7 & 27.5 & 0.5 & 14285 & + & + \\
\hline 39 & Gametocytes & $<0.1$ & + & + & 28.2 & 0.4 & 27.5 & 0.2 & 18236 & + & + \\
\hline 40 & Gametocytes & $<0.1$ & + & + & 27.6 & 0.3 & 27.9 & 1.1 & 20566 & - & + \\
\hline 41 & Gametocytes & $<0.1$ & + & + & 26.9 & 0.3 & 26.7 & 0.2 & 34485 & - & + \\
\hline
\end{tabular}


Table 1 Parasitologic factors, quantitative PCR results, and RNA transcript expression in 45 Plasmodium falciparum positive specimens with isolated gametocytemia by expert microscopy (Continued)

\begin{tabular}{llllllllllll}
\hline 42 & Gametocytes & $<0.1$ & + & - & 26.7 & 0.2 & 26.4 & 0.6 & 42605 & ND & ND \\
43 & Gametocytes & $<0.1$ & + & + & 26.3 & 0.7 & 26.2 & 0.3 & 50031 & - & + \\
44 & Gametocytes & $<0.1$ & + & + & 26.5 & 0.1 & 26.0 & 0.8 & 51397 & - \\
45 & Gametocytes & $<0.1$ & + & + & 26.2 & 0.3 & 25.5 & 0.1 & 65208 & - & + \\
\hline
\end{tabular}

ND not determined

T2 bands by RDT $(N=14)$ had a mean $C_{\mathrm{T}}$ value of 28.63 \pm 0.52 (median 28.5, range 26.2-33.2) by Plasmodium genus qPCR. Specimens with negative aldolase T2 bands by RDT $(N=30)$ had a mean $C_{\mathrm{T}}$ value of $33.05 \pm 0.53$ (median 32.5, range 26.7-39.8) $(p<0.001$ compared to those with positive aldolase $\mathrm{T} 2$ bands) by Plasmodium genus qPCR. Mean P. falciparum-specific $\mathrm{C}_{\mathrm{T}}$ value for 44 specimens was 31.04 \pm 0.49 (median 31.0, range 25.5-39.8). One specimen was undetectable by $P$. falciparum speciesspecific qPCR but was detectable by Plasmodium genus qPCR (Sample \#2, Table 1). Specimens with positive aldolase T2 bands by RDT $(N=14)$ had a mean $C_{\mathrm{T}}$ value of $28.11 \pm 0.47$ (median 28.2, range 25.5-32.4) by P. falciparum-specific qPCR. Specimens with negative aldolase T2 bands by rapid antigen test $(N=30)$ had a mean $C_{\mathrm{T}}$ value of $32.41 \pm 0.52$ (median 31.9, range 26.4-39.8) by $P$. falciparum-specific qPCR $(p<0.001)$. Mean P. falciparum $18 \mathrm{~S}$ rRNA gene copy number per reaction for the 45 specimens with isolated gametocytemia was $9073.4 \pm 2288.6$ (median 2530.0, range 4-65208). Specimens with positive aldolase T2 bands by RDT $(N=14)$ had a mean $P$. falciparum $18 \mathrm{~S}$ rRNA gene copy number of $21925.4 \pm 5386.0$ (median 12697.5, range 1195-65208). Specimens with negative aldolase T2 bands by RDT $(N=31)$ had a mean $P$. falciparum 18S rRNA gene copy number of $3269.3 \pm 1365.7$ (median 1422.0, range 4-42605) $(p<0.001)$.

\section{Quantitative real time PCR of specimens with isolated asexual stages}

Parasitemia of asexual-stage specimens ranged from $<0.1$ to $34 \%$ with Plasmodium genus $C_{\mathrm{T}}$ values from 14.1 to $28.8 ;$ P. falciparum-specific $\mathrm{C}_{\mathrm{T}}$ values from 14.5 to 28.8 , and $18 \mathrm{~S}$ rRNA gene copy number from 7287 to $50,542,052$ (Table 2). Log parasitemia was inversely correlated with both Plasmodium genus and P. falciparum-specific $C_{\mathrm{T}}$ values (Pearson $\mathrm{r}, p<0.001$ ). Furthermore, parasitemia was positively correlated with copy number (Pearson $r, p<0.001$ ). Four of 40 (10\%) specimens were negative for the aldose band on RDT, and all had low parasitemia of $<0.1 \%$. Specimens with positive aldolase $\mathrm{T} 2$ band by RDT had mean Plasmodium genus $\mathrm{C}_{\mathrm{T}}$ value of $19.31 \pm 0.52$ (median 19.2, range 14.1-25.6) and mean P. falciparum-specific $C_{\mathrm{T}}$ value of $19.46 \pm 0.51$ (median 19.1, range $14.5-26.2$ ). Specimens with negative aldolase $\mathrm{T} 2$ band by RDT had mean Plasmodium genus $\mathrm{C}_{\mathrm{T}}$ value of $26.23 \pm 1.04$ (median 26, range 24.1-28.8) and mean $P$. falciparum-specific $C_{\mathrm{T}}$ value of $26.58 \pm 0.99$ (median 26.6, range $24.3-28.8)(p<0.001$ vs those with a positive aldolase T2 band). Mean 18S rRNA gene copy number for specimens with positive aldolase T2 bands by RDT was $8,637,126 \pm 2,285,803$ (median 2,751,036, range 41,458$50,542,052)$ and for specimens with negative aldolase T2 bands by RDT was 50,109.5 $\pm 24,808.1$ (median 37,914, range $7287-117,324)(p<0.001)$. Higher asexual parasitemia was also associated with positivity of the aldolase T2 band, with 6 out of 10 (60\%) of $<0.1 \%$ parasitemia being aldolase T2 band-positive, compared to 30 out of 30 (100\%) specimens with $\geq 0.1 \%$ parasitemia being aldolase T2 band-positive (Fisher's Exact Test, $p=0.002$ ).

\section{Expression of asexual stage-specific transcripts}

An initial analysis of 3 asexual and 3 gametocytemia specimens at all three genes showed no amplification of eba- 175 on all 3 gametocytemia samples whereas pfcrt and maebl showed 3 and 2 amplifications respectively (data not shown) and thus eba-175 was chosen for further analysis. Due to the limited number of primary specimens available, a subset of 25 isolated gametocytemia and 20 asexualstages specimens were analyzed. All 20 (100 \%) asexual stages specimens, and 12 out of 25 (48 \%) isolated gametocytemia specimens demonstrated eba-175 expression (Tables 1 and 2; Fig. 1). To ensure there was no crossreactivity of human cDNA and $P$. falciparum DNA, 2 human cDNA and $8 P$. falciparum DNA extracts were tested with both eba- 175 and myosin PCR and no cross-reactivity was observed. Using microscopy as the gold standard, eba175 PCR demonstrated $100 \%$ sensitivity and $52 \%$ specificity for asexual parasitemia, with a PPV of $62.5 \%$ and NPV of $100 \%$ (Table 3). The mean band intensity in isolated gametocytemia specimens was $107 \% \pm 2.6 \%$ (median $104 \%$, range 101-133\%) and in asexual-stage specimens was $147 \% \pm 9.3 \%$ (median $134 \%$, range 101-216 \%). Thus, there was higher eba-175 transcript expression in asexualstage specimens than in isolated gametocytemia specimens (Mann Whitney, $p<0.001$ ). The mean age of individuals with eba-175 positive specimens was 37 years (range 16-61 years) versus 44 years (range 2-64 years) for eba-175 negative specimens, and these were not significantly different. 
Table 2 Parasitologic factors, quantitative PCR results, and RNA transcript expression in 40 Plasmodium falciparum positive specimens with isolated asexual-stages by expert microscopy

\begin{tabular}{|c|c|c|c|c|c|c|c|c|c|c|c|}
\hline Sample & Microscopy & Parasitemia & HRP-2 T1 & Aldolase T2 & $\begin{array}{l}\text { Plasmodium } \\
\text { Genus Mean } C_{T}\end{array}$ & StDev & $\begin{array}{l}\text { P. falciparum } \\
\text { Mean CT }\end{array}$ & StDev & $\begin{array}{l}\text { Ave } 18 \mathrm{~S} \text { rRNA } \\
\text { gene copy\#/rxn }\end{array}$ & eba-175 & myosin \\
\hline 46 & Rings & $<0.1$ & + & - & 28.8 & 0.9 & 28.8 & 0.4 & 7287 & ND & ND \\
\hline 47 & Rings, Trophs & $<0.1$ & + & - & 26.9 & 0.8 & 27.5 & 0.3 & 18727 & ND & ND \\
\hline 48 & Rings & $<0.1$ & + & + & 25.6 & 0.7 & 26.2 & 0.5 & 41458 & + & + \\
\hline 49 & Rings & $<0.1$ & + & - & 25.1 & 0.6 & 25.7 & 0.2 & 57100 & ND & ND \\
\hline 50 & Rings & $<0.1$ & + & + & 24.2 & 0.9 & 24.6 & 0.6 & 103941 & ND & ND \\
\hline 51 & Rings & $<0.1$ & + & + & 24.0 & 0.9 & 24.5 & 1.2 & 116491 & + & + \\
\hline 52 & Rings & $<0.1$ & + & - & 24.1 & 1.0 & 24.3 & 0.5 & 117324 & + & + \\
\hline 53 & Rings & $<0.1$ & + & + & 24.0 & 0.8 & 24.2 & 0.3 & 126258 & + & - \\
\hline 54 & Rings & $<0.1$ & + & + & 21.1 & 0.6 & 21.5 & 0.4 & 700623 & + & + \\
\hline 55 & Rings & $<0.1$ & + & + & 20.5 & 0.9 & 20.8 & 0.5 & 1058503 & + & + \\
\hline 56 & Rings & 0.1 & + & + & 21.5 & 1.0 & 20.7 & 0.6 & 876634 & + & + \\
\hline 57 & Rings & 0.2 & + & + & 23.6 & 1.3 & 23.2 & 0.6 & 209649 & + & + \\
\hline 58 & Rings & 0.2 & + & + & 22.6 & 1.0 & 22.3 & 0.4 & 362408 & ND & ND \\
\hline 59 & Rings, Trophs & 0.2 & + & + & 22.0 & 0.5 & 22.2 & 0.2 & 440742 & ND & ND \\
\hline 60 & Rings & 0.2 & + & + & 21.6 & 1.1 & 20.9 & 0.5 & 798231 & + & + \\
\hline 61 & Rings, Trophs & 0.3 & + & + & 20.9 & 0.7 & 21.2 & 0.2 & 818001 & + & + \\
\hline 62 & Rings, Trophs & 0.3 & + & + & 20.6 & 0.8 & 20.1 & 0.5 & 1351301 & + & - \\
\hline 63 & Rings & 0.4 & + & + & 21.2 & 0.8 & 21.8 & 0.6 & 606025 & + & - \\
\hline 64 & Rings, Trophs & 0.4 & + & + & 21.5 & 1.2 & 21.3 & 0.6 & 684146 & + & + \\
\hline 65 & Rings & 0.4 & + & + & 20.9 & 0.6 & 21.1 & 0.5 & 821066 & + & - \\
\hline 66 & Rings, Trophs & 1.1 & + & + & 18.7 & 0.9 & 18.5 & 0.5 & 3761262 & + & + \\
\hline 67 & Rings & 1.2 & + & + & 20.7 & 0.8 & 20.7 & 0.6 & 1067665 & + & - \\
\hline 68 & Rings, Trophs & 1.8 & + & + & 19.2 & 1.0 & 19.0 & 0.6 & 2758211 & ND & ND \\
\hline 69 & $\begin{array}{l}\text { Rings, Trophs, } \\
\text { Schizonts }\end{array}$ & 2.6 & + & + & 17.5 & 0.7 & 17.6 & 0.4 & 6849735 & ND & ND \\
\hline 70 & Rings, Trophs & 3.0 & + & + & 19.2 & 0.8 & 19.1 & 0.3 & 2743861 & ND & ND \\
\hline 71 & Rings & 3.0 & + & + & 17.6 & 0.4 & 18.4 & 0.2 & 5318426 & + & + \\
\hline 72 & Rings, Trophs & 3.8 & + & + & 17.2 & 0.8 & 17.5 & 0.7 & 7901115 & + & + \\
\hline 73 & Rings, Trophs & 3.8 & + & + & 17.2 & 1.0 & 17.2 & 0.4 & 9026304 & ND & ND \\
\hline 74 & Rings, Trophs & 4.0 & + & + & 17.2 & 0.8 & 17.3 & 0.8 & 8628101 & ND & ND \\
\hline 75 & Rings & 4.3 & + & + & 17.1 & 0.7 & 17.8 & 0.3 & 7438110 & ND & ND \\
\hline 76 & Rings & 10.4 & + & + & 17.4 & 1.0 & 17.3 & 0.5 & 8171936 & + & + \\
\hline 77 & Rings & 11.6 & + & + & 17.4 & 0.7 & 17.5 & 0.2 & 7541456 & ND & ND \\
\hline 78 & Rings & 12.6 & + & + & 16.6 & 0.9 & 16.6 & 0.1 & 13147859 & + & + \\
\hline 79 & Rings & 13.0 & + & + & 14.2 & 0.7 & 14.6 & 0.6 & 46984798 & ND & ND \\
\hline 80 & Rings, Trophs & 14.0 & + & + & 14.1 & 0.9 & 14.5 & 0.7 & 50542052 & ND & ND \\
\hline 81 & Rings, Trophs & 16.0 & + & + & 16.7 & 0.6 & 17.3 & 0.6 & 9825903 & ND & ND \\
\hline 82 & Rings & 18.0 & + & + & 16.9 & 1.2 & 17.2 & 0.5 & 9827129 & ND & ND \\
\hline 83 & Rings & 21.1 & + & + & 15.6 & 0.9 & 16.1 & 0.2 & 19863776 & ND & ND \\
\hline 84 & Rings & 24.0 & + & + & 14.5 & 0.7 & 14.9 & 0.3 & 39213307 & ND & ND \\
\hline 85 & Rings, Trophs & 34.0 & + & + & 14.4 & 0.5 & 14.9 & 0.5 & 41210046 & ND & ND \\
\hline
\end{tabular}

ND not fetermined 


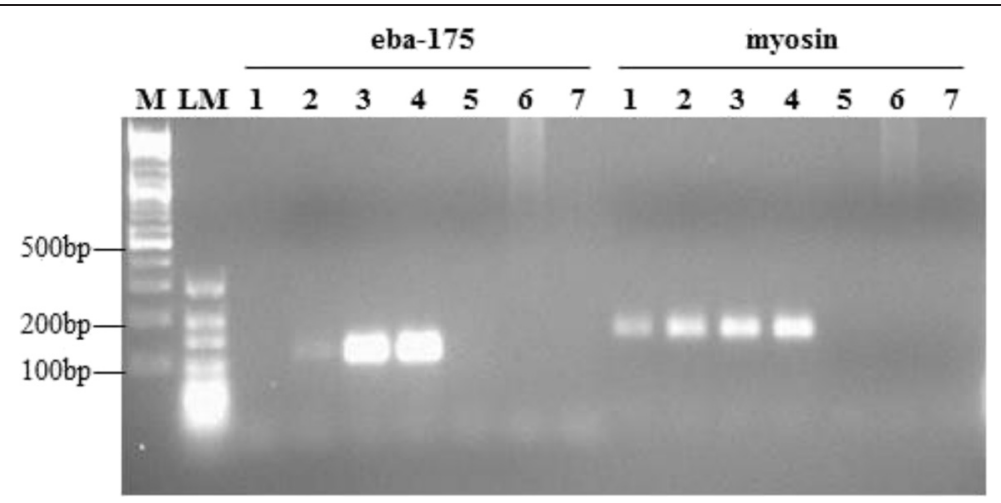

Fig. 1 Eba-175 and myosin transcript expression. M, DNA Ladder; LM, Low Range DNA Ladder; 1 and 2, isolated P. falciparum gametocytemia CDNA (sample \# 30 and 35); 3 and 4, asexual P. falciparum parasitemia CDNA (sample \# 60 and 66); 5, human cDNA; 6, P. falciparum DNA; 7, blank negative control

\section{Discussion}

Malaria is a potentially life-threatening imported infection, with 1,687 cases diagnosed in the United States in 2012, the majority of which occurred in those traveling to visit friends and relatives [13]. Malaria is an illness of particular public health importance as it is vector-borne, and has the potential to emerge in North America with expansion of the range of Anopheles vectors [14], and increasing importation from the tropics, particularly by certain high-risk types of travelers who may be semiimmune with asymptomatic parasitemia [15, 16]. Given that malaria is life-threatening, potentially emergent, and of public health importance, it is of great relevance to the health of North Americans. Asexual stages (i.e., rings, trophozoites and schizonts) are clinically relevant stages, whereas sexual stages (i.e., gametocytes) are clinically irrelevant to the human host, meaning that they do not require treatment for resolution of malaria. Gametocytes, however can be taken up by Anopheles mosquitoes via a blood meal, thus perpetuating the Plasmodium life cycle. In this regard, gametocytemia is relevant from a public health and disease transmission perspective, but has little relevance to the clinician caring for an ill patient, or the laboratorian communicating clinically relevant results back to the care team.
Microscopy remains the gold-standard diagnostic test for malaria, but with ongoing attrition of microscopy expertise in clinical laboratories across North America, hospitals and labs are increasingly reliant on non-parasitologic testing methods such as RDT and molecular assays. However, these tests cannot reliably differentiate asexual from sexual parasitemia, and are thereby limited in their clinical performance characteristics, both for new diagnoses of malaria, and for following response to treatment. Both RDT and PCR can remain positive long after successful treatment of malaria, and resolution of clinical symptoms [17]. At present, use of PCR is fairly restricted to reference laboratories, though PCR plays an increasingly important role in quality control of both microscopy and RDT, and in investigating febrile returned travelers at high risk of malaria, but with negative smear and RDT results [18]. Thus, defining and optimizing the best possible diagnostic strategies for malaria, and the life stages of Plasmodium should be a priority.

We have demonstrated that the BinaxNOW commercial RDT and a validated qPCR based on the Plasmodium $18 \mathrm{~S}$ rRNA region were unable to differentiate asexual from sexual stages of $P$. falciparum, however, the presence of the pan-Plasmodium aldolase T2 band was correlated to both higher parasitemia by microscopy and

Table 3 Performance of Plasmodium falciparum eba-175 transcript expression compared to gold-standard microscopy for identification of asexual parasitemia

\begin{tabular}{|c|c|c|c|}
\hline \multirow{2}{*}{$\begin{array}{l}\text { eba-175 transcript } \\
\text { expression }\end{array}$} & \multicolumn{2}{|l|}{ Microscopy } & \multirow{2}{*}{$\begin{array}{l}\text { Predictive } \\
\text { values }\end{array}$} \\
\hline & Isolated asexual stages (N) & Isolated sexual stages (Gametocytes) (N) & \\
\hline eba-175 Positive & 20 & 12 & $P P V^{a}=62.5 \%$ \\
\hline eba-175 Negative & 0 & 13 & $N P V^{b}=100 \%$ \\
\hline Performance Characteristics & Sensitivity ${ }^{c}=100 \%$ & Specificity $^{d}=52 \%$ & \\
\hline
\end{tabular}

${ }^{\text {a }}$ positive predictive value for asexual parasitemia, calculated as (true positives)/(true positives + false positives)

${ }^{b}$ negative predictive value for asexual parasitemia, calculated as (true negatives)/(true negatives + false negatives)

csensitivity for asexual parasitemia, calculated as (true positives)/(true positives + false negatives)

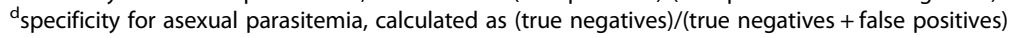


18S rRNA gene copy number. This latter finding is consistent with previous research in which the absence of the aldolase T2 band served as a reasonable basis on which to rule out high parasitemia [19]. Although RNA transcript expression of eba-175 had a low positive predictive value $(62.5 \%)$ in this study, it provided a negative predictive value of $100 \%$ for asexual stages, suggesting that it is potentially a good marker to rule-out asexual parasitemia in specimens received at the laboratory. Band intensity of eba-175 transcript expression was also greater in specimens containing asexual stages by microscopy. The low specificity (52 \%) and positive predictive value observed in this study may be explained by sub-microscopic level of asexual stages, or any residual eba-175 transcripts leftover from prior asexual stages in the isolated gametocytemia specimens. It is known that both symptomatic and asymptomatic individuals may carry sub-microscopic infections with $P$. falciparum. Moreover, sub-microscopic infections have been reported to be persistent and produce gametocytes. As microscopy and RDT are limited in their ability to detect these infections, especially in endemic populations, PCR assays have the potential to further detect submicroscopic parasitemia $[18,20]$. Furthermore, it may be possible that residual transcripts from asexual stages remain in the circulation during a patient's recovery. In an analysis comparing microscopy, RDT and qPCR results, we found that the 18S rRNA DNA can circulate in the bloodstream even after parasites are no longer observed in Giemsa-stained blood smears (Boggild unpubl. data). Given this observation, slow clearance of the eba-175 transcript may also be a possibility.

Microscopy is the gold standard for diagnosis of malaria, and identification of the different life stages is critical to provision of appropriate treatment. For instance, a patient who continues to have fever while on malaria treatment or thereafter will be managed differently if asexual parasitemia continues compared to isolated sexual-stage parasitemia. Expert microscopy demands a high level of training and skill, and in malaria nonendemic countries, this expertise is a challenge to maintain; hence, an increasing reliance on RDT and molecular assays, which may not provide adequate differentiation of asexual from sexual stages during the investigation of a febrile returned traveler, or during follow-up parasitemia while the patient is on antimalarial treatment. As microscopy expertise is lost over time in malaria non-endemic areas, PCR and RDT are being increasingly used for malaria confirmation. In those circumstances, eba-175's high NPV sufficiently excludes asexual parasitemia in a specimen that may be positive for HRP-2 antigenemia by RDT and possibly for 18S rRNA,or some other molecular target, by PCR. Thus, the ultimate goal should not be to confirm the presence of gametocytes, but rather, the absence of asexual stages such as rings and trophozoites. Further research into markers of isolated asexual or sexual parasitemia, whether RNA transcripts or expressed proteins, that provide both high positive and negative predictive values is warranted.

Several limitations of this analysis should be acknowledged. Our small sample size reflected the availability of specimens, and the limited volume of primary samples available for RNA transcript analysis. However, we included all specimens in our biobank with isolated gametocytes during the inclusion period of August 2008 to April 2014 in this study. In future, a larger sample size with time-series analysis and clinical linkage will more rigorously identify the role of eba- 175 transcript expression in the diagnosis and follow-up of malaria. Such an analysis will become more important as microscopy expertise in clinical laboratories continues to wane. Second, the low specificity and PPV of eba-175 for asexual specific-stages limits our ability to use this target as a rule-in test. On the other hand, we demonstrated $100 \%$ NPV for exclusion of asexual stages, which reinforces the utility of eba-175 as a "rule-out" test for clinically relevant stages of $P$. falciparum.

\section{Conclusions}

Asexual stage-specific eba-175 RNA transcript expression provided reasonable negative predictive value for exclusion of asexual parasitemia in clinical samples, but was present in both isolated gametocytemia and asexual stage specimens.

\section{Abbreviations}

$C_{T}$ : Cycle threshold; eba: Erythrocyte binding antigen; HRP2: Histidine rich protein 2; NPV: Negative predictive value; PCR: Polymerase chain reaction; PPV: Positive predictive value; QPCR: Quantitative real time polymerase chain reaction; RDT: Rapid diagnostic test; RNA: Ribonucleic acid; rRNA: Ribosomal ribonucleic acid.

\section{Competing interests}

The authors declare that they have no competing interests.

\section{Authors' contributions}

MP and FR contributed to data collection and analysis, and to critical appraisal of the manuscript. RL contributed to data collection, analysis, and interpretation, and to writing of the manuscript. AKB conceived the study, and contributed to data collection, analysis, and interpretation, and to writing the manuscript. All authors read and approved the final manuscript.

\section{Acknowledgments}

This work was funded by the Public Health Ontario Laboratories.

\section{Author details}

'Public Health Ontario Laboratories, Public Health Ontario, Toronto, Canada. ${ }^{2}$ Faculty of Health Sciences, McMaster University, Hamilton, Canada. ${ }^{3}$ Tropical Disease Unit, Division of Infectious Diseases, UHN-Toronto General Hospital, 200 Elizabeth Street, 13EN-218, Toronto, ON M5G 2C4, Canada. ${ }^{4}$ Department of Medicine, University of Toronto, Toronto, Canada.

Received: 1 April 2015 Accepted: 10 July 2015

Published online: 08 September 2015 


\section{References}

1. Suh KN, Kain KC, Keystone JS. Malaria. CMAJ. 2004;170(11):1693-702.

2. Humar A, Ohrt C, Harrington MA, Pillai D, Kain KC. Parasight F test compared with the polymerase chain reaction and microscopy for the diagnosis of Plasmodium falciparum malaria in travelers. Am J Trop Med Hyg. 1997:56:44-8.

3. Wongsrichanalai C, Barcus MJ, Muth S, Sutamihardja A, Wernsdorfer WH. A review of malaria diagnostic tools: microscopy and rapid diagnostic test (RDT). Am J Trop Med Hyg. 2007;77:119-27.

4. Kyabayinze DJ, Tibenderana JK, Odon GW, Rwakimari JB, Counihan H. Operational accuracy and comparative persistent antigenicity of HRP2 rapid diagnostic tests for Plasmodium falciparum malaria in a hyperendemic region of Uganda. Malaria J. 2008;7:221.

5. Iqbal J, Siddique A, Jameel M, Hira PR. Persistent histidine-rich protein 2, parasite lactate dehydrogenase, and panmalarial antigen reactivity after clearance of Plasmodium falciparum monoinfection. J Clin Microbiol. 2004:42:4237-41.

6. Thompson CA, Boggild AK. Rapid diagnostic tests in imported malaria. CMAJ. 2014;186(14):E557.

7. Khairnar K, Martin D, Lau R, Ralevski F, Pillai DR. Multiplex real-time quantitative PCR, microscopy and rapid diagnostic immunochromatographic tests for the detection of Plasmodium spp: performance, limit of detection analysis and quality assurance. Malaria J. 2009;8:284.

8. Phuong M, Lau R, Ralevski F, Boggild AK. Sequence-based optimization of a quantitative real-time PCR assay for the detection of plasmodium ovale and P. malariae. J Clin Microbiol. 2014;52(4):1068-73.

9. Shokoples SE, Ndao M, Kowalewska-Grochowska K, Yanow SK. Multiplexed real-time PCR assay for discrimination of plasmodium species with improved sensitivity for mixed infections. J Clin Microbiol. 2009;47(4):975-80.

10. Le Roch KG, Zhou Y, Blair PL, Grainger M, Moch JK, Haynes JD, et al. Discovery of gene function by expression profiling of the malaria parasite life cycle. Science. 2003;301:1503.

11. Florens L, Washburn MP, Raine JD, Anthony RM, Grainger M, Haynes JD, et al. A proteomic view of the Plasmodium falciparum life cycle. Nature. 2002:419(6906):520-6.

12. Blair PL, Witney A, Haynes JD, Moch JK, Carucci DJ, Adams JH. Transcripts of developmentally regulated Plasmodium falciparum genes quantified by real-time RT-PCR. Nucleic Acids Res. 2002;30(10):2224-31.

13. Cullen KA, Arguin PM. Malaria Surveillance - United States, 2012. MMWR Surveill Summ. 2014;63(No. SS12):1-28. Available at (accessed March 30, 2015): http://www.cdc.gov/mmwr/pdf/ss/ss6312.pdf.

14. Sutherst RW. Global change and human vulnerability to vector-borne diseases. Clin Microbiol Rev. 2004;17(1):136-73.

15. Leder K, Torresi J, Libman M, Cramer JP, Castelli F, Schlagenhauf $P$, et al. GeoSentinel surveillance of illness in returned travelers, 2007-2011. Ann Int Med. 2013;158:456-68.

16. Boggild AK, Geduld J, Libman M, McCarthy A, Doyle P, Ghesquiere W, et al Travel acquired infections and illnesses in Canadians: surveillance report from CanTravNet surveillance data, 2009-2011. Open Med. 2014;8(1):e20-32.

17. Tjitra E, Suprianto S, McBroom J, Currie BJ, Anstey NM. Persistent ICT malaria P.f/P.v panmalarial and HRP2 antigen reactivity after treatment of Plasmodium falciparum malaria is associated with gametocytemia and results in false-positive diagnoses of Plasmodium vivax in convalescence. J Clin Micro. 2001;39:1025-31.

18. Golassa L, Enweji N, Erko B, Aseffa A, Swedberg G. Detection of a substantial number of sub-microscopic Plasmodium falciparum infections by polymerase chain reaction: a potential threat to malaria control and diagnosis in Ethiopia. Malaria J. 2013;12(1):352. http:// doi.org/10.1186/1475-2875-12-352.

19. van Gool T, van Wolfswinkel ME, Koelewijn $R$, van Thiel PP, Jacobs J, van Hellemond JJ, et al. A simple and fast method to exclude high Plasmodium falciparum parasitaemia in travellers with imported malaria. Malaria J. 2011;10:300. doi:10.1186/1475-2875-10-30.

20. Shekalaghe S, Alifrangis M, Mwanziva C, Enevold A, Mwakalinga S, Mkali H, et al. Low density parasitaemia, red blood cell polymorphisms and Plasmodium falciparum specific immune responses in a low endemic area in northern Tanzania. BMC Infect Dis. 2009;9(1):69. http://doi.org/10.1186/ 1471-2334-9-69.

\section{Submit your next manuscript to BioMed Central and take full advantage of:}

- Convenient online submission

- Thorough peer review

- No space constraints or color figure charges

- Immediate publication on acceptance

- Inclusion in PubMed, CAS, Scopus and Google Scholar

- Research which is freely available for redistribution

Submit your manuscript at www.biomedcentral.com/submit 